\title{
La expansión del posesivo pospuesto a la luz de documentación navarra (y aragonesa) del siglo XIII*
}

\section{The expansion of the possessive postponed in light of Navarre (and Aragon) documentation of the thirteenth century}

\author{
ÁNGeles ROMERo CAMBróN \\ Angeles.Romero@uclm.es \\ Universidad de Castilla-La Mancha
}

\begin{abstract}
Resumen: En los primitivos documentos romances el posesivo sólo aparece antepuesto al sustantivo ("(el) nuestro padre"). La posposición ("padre nuestro") se empieza a registrar en el siglo XIII en aragonés y en dialecto navarro. Considerando principalmente la documentación de esta segunda variedad, el presente trabajo tiene como objetivo determinar el modo en que el posesivo adquirió la capacidad de aparecer pospuesto. Este cambio se vio impulsado por factores de naturaleza estructural. Uno de ellos es la existencia de la construcción posesiva con de y pronombre personal ("por raçón de mî"); otro, la concurrencia del posesivo en coordinación, bien con el sintagma preposicional ("nin subdito vuestro nin de la eglesia"), bien con otro posesivo ("l'amor nuestra e vuestra"). El posesivo se pospondría adoptando la posición propia del sintagma preposicional. Asimismo, habría influido en la imposición del cambio la tendencia a aligerar la posición prenominal cuando concurrían en ella más de un adyacente.
\end{abstract}

Palabras clave: Posesivos, sintaxis histórica, navarro, aragonés

\begin{abstract}
In the first Romance texts, possessives only occur in prenominal position (e.g. (e) nuestro padre). The earliest records of postposition (e.g. padre nuestro) date back to the 13th century in Aragonese and in Navarrese dialect. This paper reports largely on documentation involving Navarrese in order to determine in what way the postpositive placement of the possessive became normal. The influence of three grammar structures has been found to trigger possessive postposition. The first structure is a possessive construction consisting of the preposition de followed by a personal pronoun (e.g. campo de nos). The second structure includes a possessive in coordination either with a prepositional phrase (nin subdito vuestro nin de la eglesia) or with another possessive (l'amor nuestra e vuestra). In this case, the possessive occurs after the noun in the natural place of a prepositional phrase. Finally, possessive postposition became a norm to compensate noun phrases including more than one modifier in prenominal position.
\end{abstract}

Keywords: possessives, historical syntax, navarrese, aragonese.

DATA PRESENTACIÓ: 29/03/2016 ACCEPTACIÓ: 04/05/2016 · PUBLICACIÓ: 20/06/2016

SCRIPTA, Revista internacional de literatura i cultura medieval i moderna, núm. 7 / juny 2016 / pp. 1 - 20 
Ángeles Romero Cambrón. La expansión del posesivo pospuesto a la luz de documentación navarra (y aragonesa) del siglo XIII

\section{Introducción: propósito, fuentes y presupuestos teóricos}

\subsection{Los posesivos pospuestos en una consideración dialectal}

El objeto de este trabajo es dar cuenta de cómo y mediante qué pasos llegó el posesivo, desde su primitiva anteposición en romance (1), a adquirir la capacidad de aparecer pospuesto al sustantivo (2):
(1) Nuestro padre.
(2) Padre nuestro.

Previamente, antes de realizar el estudio sintáctico, hay que referirse al momento y al marco geográfico en que este proceso tuvo lugar.

En estudios más o menos recientes, se sostiene que la aparición del posesivo pospuesto al sustantivo es tardía: es el caso de Faitelson-Weiser/Lousteau (1983), Company (1991: 67; 2009a) y Huerta (2009: 689 y 701). Faitelson-Weiser/Lousteau (1983: 170, n. 6) solo registran dos testimonios de posposición tempranos, de la zona aragonesa o de tierras colindantes ${ }^{1}$ :

(3) Achel cauallero mio. (Crestomatía, 12, V, XVII, 38, 1155, documento de Soria).

(4) Las cartas mias. (Crestomatía, 25, II, 10, 1227, documento de Teruel).

Según Company (2009a: 772), la construcción aparece escasamente en el siglo XIII: los primeros testimonios empiezan a hallarse a inicios del siglo XIV y se vuelven algo más numerosos a partir de 1350. Las citadas autoras adoptan la cronología tradicional, establecida por Cornu (1884: 310) y por Menéndez Pidal (1964-1969 [1908-1911]: 257), para quienes el posesivo pospuesto era raro en el siglo XIII. Esta apreciación, claro está, tiene la validez que le otorga la base documental en la que se sustenta. Por lo que se refiere a Menéndez Pidal, al pronunciarse así, ¿estaba pensando especialmente en su conocimiento del castellano, no solo en el poema cidiano sino por ejemplo en el material reunido en los Documentos lingü̈sticos de España? En estos últimos, impresos por primera vez en 1926, sí se atestigua el posesivo pospuesto al menos en la Rioja:

(5) Por si parient mjo ujnjere ala hora demj fin. (116, 1237, Arnedo)

(6) Lesso [...] la tercera part [...] et el pedaço meo que io habeo en el moljno de Lop Lopez, et el pedaço meo que io habeo cerca laujnea dAngebjn [...] Que lo faga el mays cercano parient meo que fueret clerjgo. $(117,1240$, Alfaro)

El necesario estudio de los dialectos occidentales y orientales de la Península se abordaría con cierto retraso. El propio Menéndez Pidal (1906) dedicó una monografía pionera al leonés y encaminó a su discípulo, Navarro Tomás, al estudio del aragonés. La primera edición de los Documentos lingüisticos del Alto Aragón (DLAA a partir de ahora) estaba ya impresa en 1936, pero, desgraciadamente, esta se perdió en la contienda, y solo vio la luz más tarde de manera parcial, pues incluía únicamente

\footnotetext{
*Este artículo se ha beneficiado de la ayuda concedida por el MINECO al proyecto (FFI2011-28930).

$1{ }^{1} \mathrm{E}$ l corpus manejado en este estudio es reducido: el Cantar de mio Cid, la Fazienda y los capítulos V (1200-1230) y VI (Auto de los Reyes Magos y textos contemporáneos) de la Crestomatía de Menéndez Pidal.
} 
Ángeles Romero Cambrón. La expansión del posesivo pospuesto a la luz de documentación navarra (y aragonesa) del siglo XIII

diplomas procedentes de Huesca (Navarro Tomás, 1957)². Tomando los DLAA como principal fuente documental, en Romero (2014) puse de manifiesto cómo la posposición del posesivo (padre nuestro) era corriente en el aragonés al menos desde mediados del XIII (fecha de los primeros diplomas).

En la presente ocasión me propongo extender el ámbito geográfico de mi estudio sobre el posesivo pospuesto de Aragón a Navarra. Adopto la denominación «romance navarro» utilizada por González Ollé (1970, 1997, 1998, 1999), quien ha defendido incontestablemente la continuidad patrimonial de este desde el latín en el antiguo reino y ha sentado las bases para su conocimiento. La siguiente fase obligada en un análisis como el que esbozo sería prolongarlo al territorio riojano, histórica y lingüísticamente emparentado con Navarra y con Aragón ${ }^{3}$; ahora bien, siendo más ambiciosos, lo deseable sería la revisión de la postura tradicional a partir de nuevos testimonios documentales tanto para el castellano como para el asturiano y el leonés ${ }^{4}$.

\subsection{Fuentes}

El corpus desfrutado queda consignado en el apartado de fuentes. Comprende unos cuatrocientos documentos notariales del siglo XIII conservados en diversos archivos navarros e incluidos en las distintas publicaciones que allí se detallan. De estas colecciones he seleccionado solo los diplomas escritos en romance navarro, con exclusión de los que emplean el latín y el occitano ${ }^{5}$. Las limitaciones que este tipo de material presenta para el estudio lingüístico son de todos conocidas: permiten datar con seguridad, si pasamos por alto el problema de la autenticidad de los diplomas y del manejo de copias posteriores, como acertadamente recuerda González Ollé (1997: 672-673); ahora bien, su carácter es demasiado formulario y su contenido poco variado. El corpus no está informatizado, por lo que los testimonios se han obtenido leyendo. Semejante modo de proceder tiene la ventaja de facilitar el hallazgo de datos lingüísticos y construcciones cuya existencia no se había supuesto (como es el caso de «fillo de vos»: vid. \$2.2) y el inconveniente de hacer penosos los pormenorizados recuentos estadísticos comunes hoy en los estudios de Lingüística histórica. He tenido en cuenta también los trabajos de Saralegui (1977), Líbano (1977) y Pérez-Salazar (1993).

2 Según señala el autor en la introducción (Navarro Tomás: 1957, V-VI), desaparecieron las secciones correspondientes al Reino de Navarra, Bajo Aragón y diócesis de Segorbe, así como el borrador de un estudio sobre la historia fonética y morfosintáctica del aragonés medieval.

3 Véase Martínez Ezquerro (2000).

4 En su estudio de los posesivos en leonés, Egido (1993: 509-510) se ocupa sobre todo de la morfología y hace solo dos referencias a la posición: en los documentos del archivo catedralicio de Zamora únicamente se da el posesivo antepuesto y en Moreruela el posesivo antepuesto y el pospuesto utilizan la misma forma (no ofrece ejemplos).

5 Prescindo de documentos redactados en latín por la dificultad que entraña rastrear en ellos con seguridad vestigios de la sintaxis romance. Los occitanos constituyeron en Navarra una minoría social muy poderosa pero cerrada en relación con la población autóctona (González Ollé: 1969; 1970: 47 y 91). Ciérbide (1980: 401) da una idea de lo limitado de su actividad lingüística: de los 80.000 documentos existentes en el Archivo General de Navarra, solo 3.000 están en occitano.

SCRIPTA, Revista internacional de literatura i cultura medieval i moderna, núm. 7 / juny 2016 / pp. 1 - 20

ISSN: $2340-4841 \cdot$ doi:10.7203/SCRIPTA.7.8440 
Ángeles Romero Cambrón. La expansión del posesivo pospuesto a la luz de documentación navarra (y aragonesa) del siglo XIII

Completaré la visión obtenida acerca del romance navarro mediante una comparación sistemática con el aragonés tal como este se presenta en los DLAA, a los que sumaré, circunstancialmente, los testimonios que haya podido encontrar en dos fuentes más: la Fazienda de Ultra Mar, obra a la que se supone filiación aragonesa ${ }^{6}$, y la producción auspiciada por Juan Fernández de Heredia. De esta última no he realizado el correspondiente despojo específico por quedar fuera del límite temporal que me he fijado: solo aportaré datos de mis lecturas.

\subsection{Cambio en el orden de palabras}

Gifford y Hodcroft (1966: 127), aun subrayando que lo reducido de su antología no asegura conclusiones sólidas, señalan que un rasgo que distingue a los textos navarros frente a los aragoneses es la ausencia de la construcción artículo + sustantivo + posesivo: «a los fieles suyos». Por lo que se refiere a esta última variedad dialectal, los datos reunidos en Romero (2014) muestran cómo dicha construcción está muy presente en la producción herediana. En lo que afecta al romance navarro, Pérez-Salazar (1993: 121 y 124) rebatió ya la afirmación de Gifford y Hodcroft y lo hizo aportando cinco testimonios, entre ellos el de (7):

(7) Los comendadores suyos. $(75,1238)$.

La cuestión, con todo, es básicamente otra y debe plantearse en términos más generales: cabe preguntarse si en la documentación navarra se registra el posesivo pospuesto no solo en el contexto indicado sino también en otros. Sin haber realizado un recuento numérico por la forma en que he podido trabajar con el corpus, los testimonios reunidos me llevan a afirmar que el posesivo pospuesto existe en romance navarro, pero su implantación es menor que en aragonés (hay un centenar de casos en los DLAA, en 76 diplomas). Y lo es en un doble sentido: de una parte, la frecuencia absoluta (suma de registros); de otra, parece que no se ha extendido, o no lo ha hecho de manera tan firme, a todos los contextos sintácticos en que la posposición es posible en aragonés (vid. \$3).

Como ya anticipé arriba, el objeto de este trabajo no es revisar la cronología y la distribución dialectal de la posposición del posesivo, sino, específicamente, determinar el modo y las fases que llevaron al posesivo a acceder a esa posición. En los primitivos testimonios romances, el posesivo sólo podía ir antepuesto al sustantivo: (el) nuestro padre. La posibilidad de ocupar el margen derecho del sustantivo no surgió sin más: constituye un cambio sintáctico en la gramática de dicho adyacente. Asumo explícitamente un supuesto: si se realiza un corte sincrónico, una innovación sintáctica es más frecuente en los contextos donde antes se dio y menos en los que fue adquiriendo en sucesivas etapas de expansión. En este sentido, resulta interesante el estudio del romance navarro: si en él la presencia de la posposición es menor será posible rastrear los contextos por los que tuvo lugar su expansión.

6 Sanchis Calvo (1991) se ocupó de los posesivos en el texto.

SCRIPTA, Revista internacional de literatura $i$ cultura medieval i moderna, núm. 7 / juny 2016 / pp. 1 - 20

ISSN: 2340-4841 · doi:10.7203/SCRIPTA.7.8440 
Ángeles Romero Cambrón. La expansión del posesivo pospuesto a la luz de documentación navarra (y aragonesa) del siglo XIII

El acceso al margen derecho del posesivo es un cambio sintáctico que afecta al orden de palabras. Se trata de un cambio de importancia, como podemos ver si establecemos un paralelismo con los demostrativos. Estos pueden, efectivamente, aparecer pospuestos en la lengua moderna:

(8) El chico este siempre anda haciendo deporte.

(9) Mis años aquellos.

Por lo que respecta al periodo medieval, Faitelson-Weiser/Lousteau (1983: 172, n. 11) en su corpus del siglo XII y de principios del XIII únicamente encuentran dos testimonios de demostrativos pospuestos:

(10) Las aguas estas. (Fazienda, 173, 29)

(11) La vendita esta. (Crestomatía, 24, IV, 1219, Aguilar de Campó; ejemplo repetido cuatro veces más en el mismo documento).

Por su parte, Company (2009a ), al estudiar el sintagma nominal alfonsí, no se refiere al demostrativo pospuesto, por lo que interpreto que no lo atestigua; tampoco lo hace Bogard (2009) para el periodo medieval en su conjunto ni García Fajardo (2009). En un trabajo previo, la misma Company (1991: 67) recoge los ejemplos anteriores de Faitelson-Weiser/Lousteau (1983), pero ella misma no encuentra la construcción en un corpus más amplio en el tiempo, que alcanza hasta el siglo XV (La Celestina), y añade que no la documentan tampoco ni Menéndez Pidal (1908-1911 [1964-1969]) ni Keniston (1937) para el siglo XVI. Por mi parte, puedo añadir el único ejemplo que he logrado hallar (no he hecho una búsqueda ex profeso), que bien puede estar forzado por la rima:

(12) Tu, Señor e Dios mio que el omne formeste,

enforma e ayuda a mi, el tu arcipreste,

que pueda fazer libro de buen amor aqueste,

que los cuerpos alegre e las almas preste. (Buen amor, est. 13)

El acceso del demostrativo al margen derecho del sustantivo es, que yo sepa, cuestión pendiente de estudio. Aquí me he referido a ella solo para poner de relieve cómo el cambio de posición de un adyacente nominal implica un cambio sintáctico. Sin buscar más paralelismos para explicar el cambio sufrido por el posesivo, este no ha dado, por ejemplo, en los cardinales: «dos casas» pero «*casas dos» no ha sido posible en ningún momento de la evolución del romance.

En la exposición que sigue me referiré primero a dos factores que, según creo, están en la base de la aparición del posesivo pospuesto: la creación de las formas plenas tuyo y suyo (\$2.1.) y la continuación del genitivo con pronombre personal (\$ 2.2.). Después atenderé a las condiciones estructurales del sintagma nominal (SN) que posiblemente contribuyeron a asentar la nueva posición del posesivo: la coordinación $(\$ 2.3$.) y la pesantez $(\$ 2.4$.). Más adelante $(\$ 3)$ daré cuenta del uso de la posposición en otros contextos, esta vez analizando las propiedades del SN en su conjunto. Por último, esbozaré algunas conclusiones (\$4). 
Ángeles Romero Cambrón. La expansión del posesivo pospuesto a la luz de documentación navarra (y aragonesa) del siglo XIII

\section{La expansión del posesivo pospuesto}

\subsection{El punto de partida: creación de las formas plenas caracterizadas tuyo y suyo}

No podemos detenernos aquí en los diversos problemas que suscita la división de los posesivos en dos series, en origen, una reducida y otra plena, consolidada mediante un largo proceso histórico. Para nuestro actual propósito, basta con considerar la primera persona y la tercera del singular (la segunda, por analogía, se comporta igual que esta última). Plantearé a continuación una hipótesis, difícil de demostrar documentalmente pero muy verosímil.

En la primera persona, es la forma reducida (13) la que se hace exclusiva para la anteposición; la plena, aunque con alguna presencia en este contexto (14), se utiliza en todos los demás (15):

(13) Mi madre.

(14) En la mia enparança e en la mia guia e en la mia deffension. (Nav. II 76, 1259).

(15) Es mia.

La distancia formal entre mi y mia no es excesiva. Sin embargo, la implantación de las innovaciones tuyo y suyo supuso la existencia de una forma plena bien caracterizada en abierto contraste con la reducida. La diferenciación morfológica se vio acompañada de un reparto de funciones entre la serie reducida y la plena. Su femenino y so masculino se confunden de manera sistemática para ambos géneros. De esta forma, se llega al desdoblamiento siguiente ${ }^{7}$ :

(16) Su (so) madre./ Es suya.

(17) Su (so) padre./ Es suyo.

Cornu (1884: 313) sostenía que suyo se había originado en la función de atributo, como contestación a una pregunta realizada por cúyo: a «¿cuyó es?» la contestación sería «es suyo». De la Faz̧ienda es este pasaje con cuyo relativo, donde puede apreciarse la conexión entre los dos posesivos:

(18) Del baron cuyos son estos pennos, so yo prennada. Conocio Juda que suyos eran. (f. 4v)

La separación entre $s u(s o)$-suya, suyo debió fortalecer por analogía la existente entre mi-mia, mio. Mi se vería consolidada para la anteposición; mia-mio era la forma tradicional en el atributo («es mia», «es mio») y con artículo anafórico («la mia», «el mio»). La forma suyo tuvo que superar pronto su contexto inicial y acceder a este otro, como atestigua la misma Fazienda, desplazando a los etimológicos sua y so:

(19) Lo tuyo sea tuyo. (f. 5r)

En la documentación navarra las apariciones de so son contadas y se dan siempre en fórmulas:

(20)Qui enpues heredaren lo so. (Teo I, 98, 1244)

(21) Heredaren lo so. (1244. Apud Pérez-Salazar, 1993)

7 La presencia de sua en la anteposición se da igualmente de manera marginal:

(1) Suas gentes. (99, 1244. Apud Pérez-Salazar, 1993)

Ni Pérez-Salazar (1993) ni yo misma documentamos para las tres personas del singular femeninos en -e (mie, tue, sue).

SCRIPTA, Revista internacional de literatura i cultura medieval i moderna, núm. 7 / juny 2016 / pp. 1 - 20 
Ángeles Romero Cambrón. La expansión del posesivo pospuesto a la luz de documentación navarra (y aragonesa) del siglo XIII

Sin embargo, no hallo aún en la Fazienda el uso del posesivo adnominal pospuesto. Suyo, como forma caracterizada, pudo muy bien impulsar el acceso a esta posición y, por analogía, arrastrar a ella al resto de las personas: mio, tuyo, suyo, nuestro, vuestro, lur (o lor). Un dato viene a dar peso a la hipótesis presentada: la innovación suyo parece haberse originado justamente en el área constituida por Aragón, Navarra y la Rioja (Romero 2009), donde se documenta también antes el posesivo pospuesto.

\subsection{La influencia de la construcción posesiva «fillo de nos»}

Analicemos ahora un segundo factor que influyó probablemente en la aparición del posesivo pospuesto. El latín clásico utilizaba (de manera limitada, es cierto) el genitivo con pronombres personales de primera y segunda persona en lugar del posesivo: frequentia vostri incredibilis (Cicerón, Filípicas, IV, I) en vez de frequentia vostra incredibilis ${ }^{8}$. En romance tenemos «fillo de nos». El número de testimonios que he logrado reunir asegura la existencia de esta construcción en la lengua antigua y, desde luego, que es continuación del uso latino. Dado que en romance el sintagma preposicional (SP) va siempre pospuesto, el SP posesivo con pronombre personal favorecería el arraigo del posesivo pospuesto. La influencia no se dio a la inversa, del posesivo pospuesto sobre «fillo de nos», porque el segundo uso se documenta antes que el primero y, según parece, en un espacio geográfico más amplio.

No es extraño que «fillo de nos» perdurara en Navarra y en Aragón, donde se conserva para la tercera del plural el derivado de ILI $\square$ RUM, que no es otra cosa que un genitivo de un pronombre personal (demostrativo en origen) reanalizado como posesivo. Los ejemplos que cuentan son los de primera y segunda de singular y de plural, que mi conciencia lingüística rechazaría en español moderno (nada tienen de particular ejemplos como «de él», «de ellos», corrientes hoy). Hay testimonios antiguos:

(22) Testamentum de me et filiis meis. (n. 32, 1042, copia de la 1ª mitad del XII. Apud Ollé, 1998)

(23) Campo de nos. (n. 356, 1194, original. Apud Ollé, 1998)

En nuestro corpus he encontrado hasta nueve testimonios:

(24) Con plazenteria de nos e d'eillos. (Nav. I, 67, 1237)

(25) Cualquier otro fillo de uos. (Teo II, 1, 1253)

(26) Seremos amigos de nos et de todos uuestros amigos. (Teo. II, 1, 1253. Carta redactada en la cancillería de Jaime I de Aragón)

(27) Que ningun prestamero tienga la dicha villa por honor de nos nin merino nuestro. (Enr. 46, 1274)

(28) Pues los dias de nos. (Est., 2, 1291)

(29) Por suert e por part de mi. (Ollé 3.39, 1288, Olite)

(30) Con otorgamiento de nosotros e con otorgamiento de don Per Ortitz. (EngPam, 7, 1314)

(31) Otorgome por uuestro coyllaço de uos. (PedPam, 5, 1312)

(32) En presencia de mj, notario. (Tafalla, 12, 1340)

8 Bassols de Climent (1956: 190). 
Ángeles Romero Cambrón. La expansión del posesivo pospuesto a la luz de documentación navarra (y aragonesa) del siglo XIII

En (23) y en (26) arriba «de nos» posesivo aparece precisamente coordinado con el posesivo pospuesto adnominal. Hay al menos otro testimonio de la construcción en la Fazienda de «de vos»:

(33) Seremos siervos de ty. (Fazienda, 8v)

En los DLAA, la construcción también se atestigua al menos con tanta frecuencia como en romance navarro:

(34) Por culpa de mi. (es fórmula, 9, 1266 y passim)

(35) Apro de uos nin de los vuestros. $(23,1272)$

(36) Senes todo enbargo, nj contraria nj mala votz de mi nj de nuill omne nj muller viujentes en est siglo [...] A profeito e asaluaçion de nos ditos conpradores e delos uuestros. $(28,1274)$

(37) [...] El dito huerto, el qual auos do atreudo \& de todos sos dreytos de mj \& de todos omnes $\&$ femnas. $(31,1274)$

(38) Por raçon de mi. $(33,1274)$

Registro dos ejemplos en la prosa herediana (sin hacer una búsqueda ex profeso):

(39) Por la malvestat de los senyores de vosotros. (Emperadores, f 2d)

(40) El honor de mis parientes e de mí. (Tucídides, 50b)

«De vos» posesivo existe igualmente en otros dialectos. Para el asturiano medieval, sin dejar de reproducir los testimonios en latín del siglo XI, García Arias (1980: 540) da la construcción como abundante en la Colección Diplomática del Monasterio de San Vicente de Oviedo. Aduce ejemplos como «casa de mi» (1250), «padre de mi» $(1285,1292,1303)$ y doce testimonios más del siglo XIII y de comienzos del XIV. Un último hecho confirma la implantación de la construcción bajo examen: se documenta desde antiguo la construcción contaminada con preposición de y posesivo («de mio») en otros dialectos. En asturiano de hoy puede oírse «el neñu de mió» (García Arias: 1980); también Egido (1993: 514) da noticia de que la construcción existe actualmente en leonés y está documentada en textos medievales.

Sería preciso rastrear «de nos» posesivo en castellano. Solo dispongo del testimonio de (41):

(41) Que esca cada mes sobre la fossa de mie madre con rremembrança de mi. (DL, 154, h.1200, Burgos).

La construcción existía también en catalán medieval: Par (1923: \\ 116 y 293) la documenta en Bernard Metge y Saragossà (2000: 203-204) ${ }^{9}$ informa de su presencia en Llibre de Cort de València:

(42) Ab la qual puxe cobrir lo ventre de mi. (Metge, Lo somni, V. 478)

(43) Tu est senyor de mi e d'eyls. (Metge, Lo somni, V. 344)

\subsection{La expansión del posesivo pospuesto y la estructura del SN: la coordinación}

Los primeros testimonios de posposición del posesivo se dan en nuestro corpus en unos contextos determinados. A la vista de esta circunstancia, parece que el arraigo y la expansión del posesivo pospuesto se vieron impulsados por factores estructurales dentro del SN. Estos factores estructurales

9 Este autor da asimismo por gramatical en el valenciano de hoy el camp de nosaltres y és de vosaltres.

SCRIPTA, Revista internacional de literatura $i$ cultura medieval i moderna, núm. 7 / juny 2016 / pp. 1 - 20 
Ángeles Romero Cambrón. La expansión del posesivo pospuesto a la luz de documentación navarra (y aragonesa) del siglo XIII

son de dos tipos: de una parte, los impuestos por la coordinación; de otra, la necesidad de aliviar el peso del margen izquierdo. Si la adquisición de un orden como es el de sustantivo + posesivo modifica la estructura posicional del SN, es comprensible que se dejen sentir en su surgimiento razones de esta naturaleza. Me ocuparé a continuación del primer condicionante indicado.

\subsubsection{Coordinación del SP y el posesivo}

En nuestro corpus, los posesivos pospuestos aparecen con mucha frecuencia en coordinación y la razón está probablemente en que esta exige un paralelismo muy estrecho entre los coordinandos ${ }^{10}$. Cuando concurren un SP y un posesivo, la forzosa posposición del primero en romance induciría la del segundo. En (44), «vuestro» se coloca a la derecha de «súbdito» lo mismo que lo hace «eglesia de Pamplona»:

(44) E otrossi que ningun uassaillo nin subdito vuestro nin de la eglesia de Pamplona. (Enr. 4, 1271)

(22) arriba, repetido aquí por comodidad, muestra este mismo esquema:

(45) Testamentum de me et filiis meis.

De los DLAA son estos dos ejemplos de SP y posesivo pospuesto, en distintos esquemas:

(46) En tiempo del Seynor rey don Jaime \& suyo. $(55,1283)$

(47) Prometo en fe de Dios \& fialdat mja. $(33,1275)$

\subsubsection{Dos posesivos en los coordinandos}

En la lengua medieval era posible una estructura coordinada como la de (48):

(48) Quanto compraro et ganaro en mios dias \& sos. (DL, 17, h. 1196, Cervera del Río, Campó)

Entiéndase 'en mis días y en los suyos'. En ella en el primer coordinando aparece un posesivo antepuesto («mios dias ») y en el segundo un posesivo sin artículo(«sos»). Sobre lo singular de esta construcción llamó por primera vez la atención Fernández Ramírez (1985-1986 [1951] 3.2: 94). Los testimonios que he reunido abarcan un amplio arco temporal ${ }^{11}$ :

(49) So padre et mio. (Ollé, 3.5. 1210)

(50) Los pobres que comen a la puerta de la casa de mi padre e mía. (apud Fernández Ramírez, 3.2: 94$)$

(51) El rey tu marido ha fecho grant crueldat \& inhumanidat en matar sus fillos \& tuyos. (Grant Crónica de Espanya I, 24v).

(52) Por la cruel muert que tu diste a tus fillos e mios. (Grant Crónica de Espanya I 24v)

(53) Más merece Calixto e su ruego e tuyo. (Celestina, acto V)

Sin embargo, en nuestro corpus navarro se da esta otra estructura donde el posesivo del primer coordinando no aparece antepuesto sino pospuesto («mandaderos nuestros», «razones nuestras»):

10 Esta exigencia de la coordinación fue abordada por Goodall (1987). Vid. Camacho (1999).

11 Esta construcción es la que parece documentarse en (1):

(1) Ad Sancio Acenariz, suo germano et meo. (84, 1068 original; copia de la primera mitad del XII. Apud, Ollé, 1998). 
Ángeles Romero Cambrón. La expansión del posesivo pospuesto a la luz de documentación navarra (y aragonesa) del siglo XIII

(54) Embiamos nuestros mandaderos a la cort de Roma, seguiendo eillos su apellation que dicen que an fecha, e los mandaderos nuestros e suios digan las razones nuestras et suias. (Nav. I 71, 1238)

Entiéndase 'nuestros mandanderos y los suyos', 'nuestras razones y las suyas'. He aquí un segundo ejemplo:

(55) L’amiztat e l'amor nuestra e muestra. (Teo II 1, 1253, redactado por la cancillería de Jaime I).

\subsection{La expansión del posesivo pospuesto y la estructura del SN: los problemas de pesantez.}

Fuera ya de la coordinación, otro factor se dejó sentir, probablemente, en el surgimiento de la posposición: la tendencia a evitar la pesantez del margen izquierdo del SN cuando en este concurrían determinantes y complementos en diferente número. Se trata, claro, de tendencias en alternancia y no de reglas posicionales fijas ${ }^{12}$. Partamos de un margen izquierdo sobrecargado como el de (56), donde hay un complemento pesado («mucho amada») y dos determinantes («la» $\mathrm{y}$ «vuestra»):

(56) Éncuba, la vuestra mucho amada muller. (Heredia, Troyana 95d).

Parece observarse que, en estos casos, la tendencia del posesivo a posponerse es mayor. Así, en (57), como «muy noble» precede a «padre», «nuestro» le sigue; asimismo, como «muy caro» precede a «ermano» «nuestro» le sigue:

(57) Viemos e catamos las letras del muy noble padre nuestro don Thibalt qui fue rey de Navarra e de cabo las letras de don Thibalt muy caro ermano nuestro, del rey don Sancho nuestro visabuelo. (Enr. 18, 1271)

Otro tanto ocurre en (58), del mismo documento, y en (59), de un documento algo posterior:

(58) Las letras de don Thibalt, muy caro padre nuestro, rey de Nauarra, e del rey Sancho nuestro uisauuelo. (Enr. 18, 1271)

(59) Al muyt alto et muy poderoso et excellent prinçep et seynor nuestro natural, don Philipe. (Pam. 111, 1319)

En (69) y (61) «tios nuestros» y «sobrinos nuestros» son aposiciones a la derecha de SSNN muy pesados, sobre todo en el margen izquierdo:

(60) Auido conseio et deliberation con los honrrados don Pero Sanchez, dean de tudela, et don Pero Sanchec freyre de la orden de Roncesualles, tios nuestros et muchos otros parientes nuestros et amigos [...] Rogamos a los hondrados et savios don Pero Sanchez, dean de Tudela, et don Pero Sanchec freyre de la orden de Roncesualles, tios nuestros... E nos don Pero Sanchez, dean de Tudela, et don Pero Sanches freyre de la orden de Roncesualles, a rogarias de los dichos iohan Sancheç et Milla Sancheç, sobrinos nuestros. (Nav. III, 76, 1278)

(61) Rogamos al honrrado et sabio uaron don Pero Sanchiz de Montagud, dean de Tudela, tio nuestro [...] Io don Pero Sanchiz, [dean a peticion] de Ioban Sanchiz et de Milla Sanchir, sobrinos mios. (Nav. III 78,1278$)$

12 Una primera presentación a los problemas de colocación dentro del SN es la que ya anticiparon Hernanz y Brucart (1987: 145-171).

SCRIPTA, Revista internacional de literatura i cultura medieval i moderna, núm. 7 / juny 2016 / pp. 1 - 20 
Ángeles Romero Cambrón. La expansión del posesivo pospuesto a la luz de documentación navarra (y aragonesa) del siglo XIII

Es posible que fuera también una tendencia a simplificar el margen izquierdo la que llevó a la posposición del posesivo cuando concurría con un cuantificador. Con el posesivo antepuesto, tanto con el orden de (62) abajo, como con el de (63)-(65) el margen izquierdo era muy pesado:

(62) Las nuestras otras cosas. (1237. Apud Pérez-Salazar, 1993)

(63) Los otros nuestros anteccessores. (1238. Apud Pérez-Salazar, 1993)

(64) La otra su peyta que nos paga por la fiesta de Sant Miguel. (Nav. II 38, 1264 Pamplona)

(65) Con todos los otros sus dreychos. (Enr. 55, 1274)

(66) Si por uentura algun lur confrade fues mingoado. (Enr. 53, 1274)

(63)-(66) ilustran el orden presumiblemente más antiguo y el más frecuente, con el cuantificador precediendo al posesivo, pero se documenta también la construcción con el posesivo pospuesto, como en (67)-(69) abajo. Existe, claro está, la construcción partitiva (70):

(67) De los sobredichos nuestros tios et de otros parientes et amigos nuestros [...] Otros parientes nuestros et amigos. (Nav. III 76, 1278)

(68) Muchos otros parientes nuestros et amigos. (Nav. III, 76, 1278)

(69) No atendiendo otro mandamiento nuestro sobr'esto ni de d'otri nenguno qui tenga el nuestro logar (Enr. 50, 1274)

(70) Si por auentura alguno de lures confrades fuesse mingoado. (Enr. 53, 1274).

No dispongo de ningún ejemplo del corpus con cardinal, ni en uno ni en otro orden señalado («un su campo» o «un campo suyo»). Sí los hay en los DLAA:

(71) Tres campos nuestros. $(23,1272)$.

(72) Una vigna nuastra. $(9,1266)$

(73) Vna tienda nuestra. $(25,1273)$

(74) Vn campo nuestro que auemos. $(63,1292)$.

Dispongo, sí, de un testimonio del tercer orden posible (posesivo + cardinal):

(75)Nuestras dos ruedas que avemos. (118, 1247, Puente de la Reina. Apud Pérez-Salazar 1993)

Ahora bien, nótese que la interpretación de (75) es definida ('las dos ruedas nuestras que tenemos') y no indefinida como en (66) arriba por ejemplo ('algún cofrade suyo'). Desempeña un papel determinante en la posición del posesivo la oración relativa que, en la lengua moderna, permite solo el posesivo pospuesto, como en (74) arriba o en (76) abajo, esta vez con artículo en lugar de cuantificador:

(76) Otorgamos al conceillo de Sanguesa el molino nuestro que es dicto Trapero. (Nav. II

29, 1264)

Por otra parte, aunque este no sea el único motivo que pudo conducir a su aparición, es evidente que el esquema artículo + sustantivo + posesivo responde a la misma estructura de reparto de la pesantez entre los dos márgenes que se da con el cuantificador en (67)-(69) arriba:

(77) Los comendadores suyos. $(75,1238)$.

Sobre las razones que impulsaron la aparición de (77) habré de volver. Hay, sin embargo, un contexto donde la anteposición se mantiene a pesar de que el margen izquierdo es muy complejo: el representado por el artículo con el participio de dęir, con valor anafórico. Así en (78)-(80):

SCRIPTA, Revista internacional de literatura $i$ cultura medieval i moderna, núm. 7 / juny 2016 / pp. 1 - 20 
Ángeles Romero Cambrón. La expansión del posesivo pospuesto a la luz de documentación navarra (y aragonesa) del siglo XIII

(78) Los dichos nuestros labradores. (Nav. II 18, 1256, Olite)

(79) Los sobredichos nuestros tios. (Nav. III 76, 1278)

(80) Al dicho mjo procurador [...] por el dicho mjo procurador. (PedPam 9, 1330)

El carácter formulario y estereotipado de la expresión explican el mantenimiento del posesivo antepuesto. Tengo registrado solo un testimonio tardío donde lo que se pospone es el participio:

(81) Las antedichas mj madre et mjs hermanas [...] Mis hermanas antedichas. (PedPam 7, 1312)

En los DLAA sí registro el posesivo pospuesto con dicho anafórico, aunque lo habitual, con diferencia, sea la anteposición:

(82) El dito capellan nuestro. $(12,1268)$

(83) Los dictos bienes mios que romanen. $(49,1279)$

\section{Expansión a otros contextos: SSNN escuetos y SSNN definidos}

En los apartados anteriores he pretendido dar cuenta de los mecanismos que actuaron en el acceso del posesivo al margen nominal derecho, como son la influencia del SP posesivo «fillo de nos» o las razones estructurales examinadas. Una vez alcanzada dicha posición, ¿qué condiciones sintácticas propiciaban el empleo del posesivo posnominal? Intentaré clasificar los testimonios del corpus que he manejado para llegar a alguna conclusión.

De entrada, el posesivo pospuesto aparece en el corpus en SSNN escuetos (es decir, sin determinación $)^{13}$. Esto ocurre en dos supuestos distintos. En primer término, se da con SSNN con referencia inespecífica, es decir, en aquellos donde no se está aludiendo a un individuo en particular sino a alguien o a algo a quien se le pueda aplicar el contenido atributivo del $\mathrm{SN}^{14}$.

Es lo que sucede en el siguiente caso. Jaime I el Conquistador está concertando con la reina Margarita de Navarra el matrimonio de su hija Constanza y Teobaldo II. Ante cualquier eventualidad, la alianza no se alteraría: el lugar de Constanza lo ocuparía otra princesa aragonesa y el de Teobaldo quien efectivamente ocupe el trono navarro. En términos gramaticales, se entiende que un sustantivo como fillo tiene referencia inespecífica (esto es, no se señala a un individuo en particular sino a alguien que cumpla con el requisito de ser el heredero del trono: 'la persona que llegue a ser rey de Navarra', no necesariamente Teobaldo II):

(84) [En matrimonio] uos daremos nuestra filla dona Costança por muyller a leyal matrimonio, al deuandicto uuestro fillo Thibalt, rey de Navarra, o a qualquier otro unestro fillo que sera rey de Nanarra, si don Thibalt muria. [Si el matrimonio con Constancia no fuera posible, os daremos] nuestra filla dona Sancha al deuandicto uuestro fillo Thibalt, rey de Navarra, o a qualquier otro unestro fillo que sea rey de Nanarra [...] Qualquier otro fillo nuestro qui sera rey de Navarra [...] Nos et el fillo nuestro que será rey de Nanarra. (Teo II 1, 1253)

13 Sobre el sustantivo sin determinación, vid. Bosque (1996).

14 El concepto de referencia específica e inespecífica es bien conocido en gramática. Véase, Leonetti Jungl (1990: 49).

SCRIPTA, Revista internacional de literatura i cultura medieval i moderna, núm. 7 / juny 2016 / pp. 1 - 20 
Ángeles Romero Cambrón. La expansión del posesivo pospuesto a la luz de documentación navarra (y aragonesa) del siglo XIII

Asimismo, en (85) abajo «parienta suya» es referencia inespecífica, al igual que «ermana de don Alfonso»; en (86) «merino o baille nuestro» es 'alguien que fuera merino o baile nuestro'; en idéntica situación está «mandamiento» en (87):

(85) Si el dicto matrimonio nos podie fer por aquello que el dicto fillo nuestro no end ouies conseillo ... prometemos ... que unquas en ningun tiempo de su uida no case con ermana de don Alfonso, rey de Castiella, de leyal coniunio o non de leyal coniunio ni con parienta suya que sea filla de nuyl rey ni de nuil homne d'Espaynna qui sea morador en Espayna... senes uuestra uolontat. (Teo II 1, 1253)

(86) Si merino o baille nuestro peyndrare por peycta que deuan en la villa, non deue sacar peynnos de la villa. (Nav. II 18, 1256)

(87) Quando mandamiento suyo fuesse. (Enr. 4, 1271)

Un segundo contexto donde, en la lengua antigua y también en la de hoy, aparece el sustantivo escueto es en el término del $\mathrm{SP}^{15}$. En este caso, en romance navarro, como puede verse en los testimonios siguientes, el posesivo pospuesto se va introduciendo como solución todavía minoritaria que solo se hace más frecuente a finales del siglo XIII:

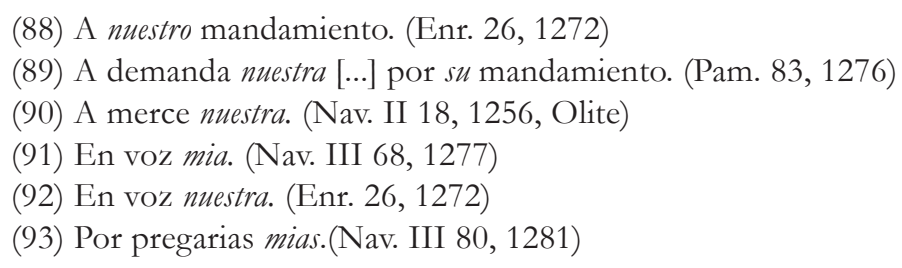

Sin embargo, en el extremo contrario al representado por el empleo con SSNN escuetos, el posesivo pospuesto dio un paso más y se extendió a SSNN definidos. Es lo que ocurre de manera inequívoca con referentes consabidos y únicos (solo hay una madre). En (94) se da la posposición no solo con «filla» o «ermana», sino también con «nodriça» y «madre»:

(94) Ab Elbira nodriça mia [...] Kathelina filla mia [...] la dita Milla, ermana mia [...] las ditas casas a la dita Milla, ermana mia [bis]. Por las animas de Domingo Pon [mi padre et de] Milla mi ermana et de todos mis anteccesores [...] finados los dias de Milla, mi ermana [bis] [... ] El resto que se de a dona Sancha, madre mia. (Nav. III 80, 1281)

En este sentido, conviene subrayar un dato importante: la posposición con SSNN definidos es mucho más frecuente en aragonés que en romance navarro, aunque en las dos variedades alterna con la anteposición. La primera opción (95) es ya la ordinaria en los DLAA, frente a la segunda (96):

(95) Damos \& otorgamos [...] vn campo nuestro [...] auos don Martin de Ygries \& amuller uuestra dona Pelegrina, \& auos don Johan de Tuuo \& amuller unestra Domenja. (34, 1275).

(96) Damos \& otorgamos a uos don Sanyio de Castiello \& vuastra mullier Domenia. $(30,1274)$

También en (97)-(99) el valor definido es innegable. El primero de los testimonios es navarro y los dos siguientes aragoneses:

(97) Pues vuestra vida [...] apres vuestros dias [...] apres dias tuyos. (Ollé 3.35, 1275)

(98) Apres dias tuyos [...] apres dias vuestros. (DLAA 25, 1273).

15 Para el estudio del sustantivo escueto en la lengua actual en el SP, vid. Bosque (1996a: 49-56).

SCRIPTA, Revista internacional de literatura i cultura medieval i moderna, núm. 7 / juny 2016 / pp. 1 - 20 
Ángeles Romero Cambrón. La expansión del posesivo pospuesto a la luz de documentación navarra (y aragonesa) del siglo XIII

\author{
(99) En esta carta sin+ nal nuastro femos. (DLAA 29 y,30, 1274, mismo notario), es decir, \\ 'hacemos nuestro signo'(el único que tiene el notario). El posesivo pospuesto en SSNN \\ definidos sigue muy presente en la prosa herediana: \\ (100) Herenio, padre suyo. (Eut., f. 23b). \\ (101) Su ermana Costancia era muger suya. (Eutr. f. 63d).
}

El análisis de los testimonios recogidos en el presente apartado lleva a concluir que el uso del posesivo pospuesto no está en función de las propiedades referenciales ni del carácter definido o no definido del SN; la anteposición y posposición alternan libremente como dos opciones en el orden de palabra. Es lo que ocurre, para poner un ejemplo claro, en (95) arriba: «vuestros dias» es equivalente a «dias tuyos» (con la sola diferencia del posesivo empleado, claro), en contraste con lo que sucede en el español actual. A que se trata de una simple alternancia posicional apuntan sintagmas como (102), donde la pesantez del SN desplaza al margen derecho, en vez de al posesivo, al cuantificador (el documento es el mismo del que se extrae (84) arriba), en un orden que no admitiría la lengua moderna:

(102) Unestro fillo qualquier que sera rey de Navarra. (Teo II 1, 1253)

Finalmente, en la sintaxis del posesivo la existencia de construcción artículo + sustantivo + posesivo no enfática («los comendadores suyos») es un hecho notable por dos razones: de un lado, revela la actuación de las fuerzas que reequilibran los márgenes nominales izquierdo y derecho, pues el sustantivo es precedido por el determinante y seguido por el posesivo, al igual que sucede con el cuantificador («un campo nuestro»); de otro, ha de entenderse como el surgimiento de una construcción inequívocamente definida, ante el avance de la posposición sin artículo en SSNN definidos, como «muller vuestra» (95 arriba).

\title{
3. Conclusiones
}

Los resultados del estudio precedente están condicionados, ocioso es decirlo, por la naturaleza y extensión del corpus tomado como base. Aun así, creo que pueden extraerse algunas conclusiones. El posesivo pospuesto («padre nuestro») existe en romance navarro con considerable difusión. Desde luego, su presencia no se reduce a la construcción artículo + sustantivo + posesivo. Con todo, es menos frecuente que en aragonés en términos absolutos. Por lo que se refiere a su sintaxis, en contraste también con esta última variedad, su uso con SSNN definidos («madre mia», «dias suyos») es escaso. De otro lado, considerando la respectiva frecuencia, si el uso está más asentado en Huesca que en Navarra, es de suponer que el foco de irradiación estuvo en tierras aragonesas.

El propósito de este trabajo ha sido dar de cómo y mediante qué pasos o fases había adquirido el posesivo, a partir de la anteposición («nuestros padres») la facultad de aparecer pospuesto («padres nuestros»). El afianzamiento del desdoblamiento morfológico de los posesivos en una serie plena y otra reducida, impulsado de manera definitiva con la adopción de los analógicos tuyo y suyo, se vio acompañada de un reparto de contextos entre ambas, por lo que este desdoblamiento formal 
Ángeles Romero Cambrón. La expansión del posesivo pospuesto a la luz de documentación navarra (y aragonesa) del siglo XIII

funcionó con seguridad como condición previa a la colocación del posesivo en el margen derecho. Si lo que se ha producido es un cambio en la estructura del SN, lo esperable sería que sean factores de esta naturaleza los que han dejado sentir su peso en el cambio posicional sufrido por el posesivo: la existencia de «fillo de nos» posesivo, la coordinación y el reequilibrio de los márgenes izquierdo y derecho.

Por lo que se refiere al procedimiento seguido en este estudio, se podrá objetar que el grado de especulación en que se ha desenvuelto es alto, por cuanto no se llegan a demostrar en él las conclusiones documentalmente, o no de manera suficiente o concluyente. La fuerza probatoria ha de buscarse no en una sino en la suma de las evidencias aportadas. En términos generales, la especulación es inevitable en sintaxis histórica en la medida en que el gramático procura refinar el análisis de unos datos que siempre son pobres y parciales. 
Ángeles Romero Cambrón. La expansión del posesivo pospuesto a la luz de documentación navarra (y aragonesa) del siglo XIII

\section{Fuentes.}

\section{Corpus Navarro}

EngPam = Documentación medieval del monasterio de Santa Engracia de Pamplona (siglos XIII-XVI), Ricardo Ciérbide y Emiliana Ramos (eds.), San Sebastián, Eusko Ikaskuntza- Sociedad de Estudios Vascos, 1997.

Enr. = Colección diplomática de los reyes de Navarra de la dinastía de Champaña Enrique I de Navarra (12701274), Javier Zabalo Zabalegui, San Sebastián: Eusko-Ikaskuntza=Sociedad de Estudios Vascos, 1987.

Est $=$ Documentación medieval del Monasterio de Santa Clara de Estella (siglos XIII-XVI), Ricardo Ciérbide y Emiliana Ramos (eds.), San Sebastián, Eusko Ikaskuntza- Sociedad de Estudios Vascos, 1996.

Nav. I = Archivo General de Navarra: 1234-1253. II. Comptos y cartularios reales, María Raquel García Arancón, San Sebastián, Eusko Ikaskuntza, 1998.

Nav. II = Archivo General de Navarra: 1253-1270, María Raquel García Arancón, San Sebastián, Eusko Ikaskuntza, 1996.

Nav. III = Archivo General de Navarra: 1274-1321, M. Itziar Zabalza Aldave, San Sebastián, Eusko Ikaskuntza, 1995.

Ollé= González Ollé, Fernando (1970) Textos lingüisticos navarros, Pamplona, Institución Príncipe de Viana.

Pam. $=$ Documentación medieval del Archivo Municipal de Pamplona, recopilación y transcripción de Ricardo Ciérbide y Emiliana Ramos, San Sebastián, Eusko Ikaskuntza- Sociedad de Estudios Vascos, 2 vols., 1998-2000.

PedPam = Documentación medieval del Monasterio de San Pedro de Ribas de Pamplona (siglos XIII-XVI), Ricardo Ciérbide y Emiliana Ramos (eds.), San Sebastián, Eusko Ikaskuntza- Sociedad de Estudios Vascos, 1998.

Taf.= Archivo Municipal de Tafalla (1157-1540), Ricardo Ciérbide y Emiliana Ramos (eds.), San Sebastián, Eusko Ikaskuntza- Sociedad de Estudios Vascos, 2001.

Teo I = Colección diplomática de los reyes de Navarra de la dinastía de Champaña. Teobaldo I (1234-1253), Margarita Martín González, San Sebastián, Eusko Ikaskuntza- Sociedad de Estudios Vascos, 1987.

Teo II = Colección diplomática de los reyes de Navarra de la dinastía de Champaña Teobaldo II (1253-1270), Mª Raquel García Arancón, San Sebastián, Eusko Ikaskuntza-Sociedad de Estudios Vascos, 1987.

\section{CORPUS ARAGONÉS}

Eut: Eutropio y Paulo Diácono: Compendio de historia romana y longobarda. Versión aragonesa patrocinada por Juan Fernández de Heredia. Edición de Marcos J. Herraiz Pareja y Adelino Álvarez Rodríguez. Estudio y glosario de Marcos J. Herraiz Pareja, inédito. 
Ángeles Romero Cambrón. La expansión del posesivo pospuesto a la luz de documentación navarra (y aragonesa) del siglo XIII

Fazienda = Fazienda de Ultra mar, ed. de Moshé Lazar, Salamanca: Acta Salmanticensia,1965.

Navarro Tomás, Tomás 1957 Documentos lingüisticos del Alto Aragón, Syracuse-New York, Syracuse University Press.

Grant Crónica de Espanya I (primera partida). En Nitti, John J./Lloyd A. Kasten The electronic texts and concordances of Medieval Navarro-Aragonese manuscripts Madison, Hispanic Seminary of Medieval Studies, 1997. [http://www.hispanicseminary.org/t\&c/nar/index-es.htm].

Plutarco. Vidas semblantes. Versión aragonesa de las Vidas paralelas, patrocinada por Juan Fernández de Heredia. Edición de Adelino Álvarez Rodríguez, Zaragoza, PUZ, 2009, 2 vols.

Troyana. Juan Fernández de Heredia, Crónica troyana, ed. de María Sanz Julián, PUZ, 2012.

Tucídides. Discursos de la guerra del Peloponeso. (Versión aragonesa de la Historia de la guerra del Peloponeso, patrocinada por Juan Fernández de Heredia). Edición crítica y estudio de Adelino Álvarez Rodríguez, Zaragoza, PUZ, 2007. 
Ángeles Romero Cambrón. La expansión del posesivo pospuesto a la luz de documentación navarra (y aragonesa) del siglo XIII

\section{Referencias bibliográficas:}

Bassols de Climent, Mariano (1996 [1956]) Sintaxis latina, Madrid, CSIC.

Bogard, Sergio (2009) «La frase nominal con núcleo sustantivo común», en Concepción Company, 2009, 57-270.

Bosque, Ignacio, ed. (1996) El sutantivo sin determinación, Madrid, Visor.

- (1996a) «Por qué determinados sustantivos no son sustantivos determinados. Balance y repaso», en Bosque, 1996, p. 13-120.

Bosque, Ignacio y Violeta de Monte, eds. (1999) Gramática descriptiva de la lengua española, Madrid, Espasa, 3 vols.

Camacho, José (1999) «La coordinación», en Bosque, Ignacio y Violeta de Monte, eds., II, p. 26352694.

Ciérbide Martinena, Ricardo (1980) «En torno a la problemática lingüística en la Navarra medieval», Fontes linguae vasconum, 12 (35-36), p. 395-402.

Company Company, Concepción (1992) La frase nominal en el español medieval. Cuatro cambios sintácticos, Méjico, Universidad Nacional Autónoma de Méjico.

- dir. (2009) Sintaxis histórica de la lengua española. Segunda parte: La frase nominal, México, FCE y Universidad Nacional Autónoma de México, 2 vols.

- (2009a) «La estructura nominal de la frase nominal alfonsí. Esbozo de diacronía», en Concepción Company, 2009, I, p. 3-56.

Cornu, Jules (1884) «Les possessif en ancien espagnol», en «Melanges espagnols», Romania, 13, p. 307-313.

Egido Fernández, María Cristina (1993) «Los posesivos en la documentación medieval leonesa», en Gerold Hilty (ed.) Actes du XX Congrès International de Linguistique et Pbilologie Romanes, II, Tubinga, Narr, p. 505-516.

Faitelson-Weiser, Silvia y Roselyne Lousteau (1983) «Les CNm à détermination multiple en ancien espagnol», Langue et Linguistique, 9, p. 143-175.

Fernández Ramírez, Salvador (1986-1987 [1951]) Gramática española (ed. ordenada y compilada por Ignacio Bosque y José Polo), Madrid, Arco-Libros.

García Arias, José Luis (1980) «Dos notes de sintaxis diacrónica n’asturiano», Archivum, 29-30, p. 535-545.

García Fajardo, Josefina (2009) «Los demostrativos. Funciones y valores referenciales», en Concepción Company, 2009, p. 465-608.

Gifford, D. J. y F. W. Hodcroft (1966²) Textos lingüísticos del medioevo españolpreparados con Introducción y Glosario, Oxford, The Dolphin. 
Ángeles Romero Cambrón. La expansión del posesivo pospuesto a la luz de documentación navarra (y aragonesa) del siglo XIII

González Ollé, Fernando (1970 «El romance navarro», RFE, 53, p. 45-93.

—_. (1969) "La lengua occitana en Navarra", RDTP, 25, p. 285-300.

—. (1970) «La función de Leire en la génesis y difusión del romance navarro, con noticia lingüística de su documentación (I)», Príncipe de Viana, 58 (213), p. 653-708.

—_.(1998) «La función de Leire en la génesis y difusión del romance navarro, con noticia lingüística de su documentación (II)», Príncipe de Viana, 59 (214), p. 483-522.

—_.(1999) «La función de Leire en la génesis y difusión del romance navarro, con noticia lingüística de su documentación (III)», Principe de Viana, 60 (218), p. 757-822.

Goodall, Grant (1987) Parallel Structures in Syntax, Cambridge, Cambridge University Press.

Hernanz, Maria Lluïsa y José María Brucart (1987) La sintaxis. 1. Principios teóricos. La oración simple, Barcelona, Crítica.

Huerta Flores, Nohorella (2009) «Los posesivos». En Company, Concepción, I, p. 609-757.

Keniston, Hayward (1937) The Syntax of Castilian Prose: The Sixteenth Century, Chicago, University of Chicago Press.

Leonetti Jungl, Manuel (1990) El artículo y la referencia, Madrid, Taurus.

Líbano Zumalacárregui, Ángeles (1977) El romance navarro en los manuscritos del fuero antiguo del Fuero General de Navarra, Pamplona, Diputación Foral- Príncipe de Viana-CSIC.

Martínez Ezquerro, Aurora (2000) «Afinidades entre los dialectos riojano y aragonés medievales», AFA, 56, p. 79-94.

Menéndez Pidal, Ramón (1906) El dialecto leonés, Revista de Archivos, Bibliotecas y Museos, 14 (2-3).

—. (1964-1969 [1908-1911]) Cantar de Mio Cid: texto, gramática y vocabulario, Madrid.

—. (1985 [1965]) Crestomatía del español medieval, 2 vols., Madrid, Gredos.

—. (1966 [1926]) Documentos lingü̈sticos de España. I. Reino de Castilla. Madrid, CSIC.

Par, Alfóns (1923), Sintaxi catalana segons los escrits en prosa de Bernard Metge, Halle, Max Niemeyer.

Carmela Pérez-Salazar Resano (1993) «Rasgos morfosintácticos y léxicos del romance navarro (primer tercio del siglo XIII)», Principe de Viana, 54 (198), p. 111-184.

Romero Cambrón, Ángeles (2009) «Sobre el origen de los posesivos tuyo y suyo», Cabiers d'Études Hispaniques Médiévales, 32, p. 83-100.

—_. (2014) «Los posesivos en la producción herediana (ensayo de panorámica general sobre el aragonés)», ZRh, 130 (2), p. 352-369.

Sanchis Calvo, M. ${ }^{a}$ Carmen (1991), El lenguaje de la Fazienda de Ultra Mar, Madrid, BRAE, anejo XLIX. 
Ángeles Romero Cambrón. La expansión del posesivo pospuesto a la luz de documentación navarra (y aragonesa) del siglo XIII

Saragossà, Abelard (2000) «Els adjectius possessius: naturalesa teòrica i aplicació a la normativa i al català col.loquial», Llengua \& Literatura, 11, p. 199-280.

Saralegui, Carmen (1977) El dialecto navarro en los documentos del Monasterio de Irache (958-1397), Pamplona, Diputación Foral- Príncipe de Viana-CSIC. 